\title{
A cooperação entre Brasil e Estados Unidos no campo da saúde: o Serviço Especial de Saúde Pública e a política sanitária no governo Vargas
}

\author{
Cooperation between Brazil and the US in the health \\ field: the Serviço Especial de Saúde Pública and the \\ Vargas administration's sanitary policy
}

\author{
Regina Érika Domingos de Figueiredo \\ Doutoranda do Instituto de Filosofia e \\ Ciencias Humanas da Universidade de Campinas - Unicamp \\ erikafido@yahoo.com
}

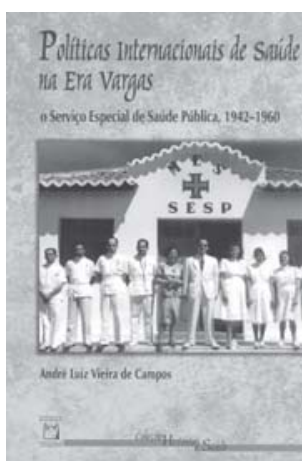

Campos, André Luiz Vieira de.

Politicas internacionais de saúde na era Vargas: o Serviço Especial de Saúde Pública, 1942-1960.

Rio de Janeiro: Ed.

Fiocruz, 2006. 318p.
E m 1942, nos bastidores da Segunda Guerra Mundial, o governo dos Estados Unidos, por meio do Instituto de Assuntos Interamericanos (Iaia), estabeleceu convênios bilaterais com 18 repúblicas latinoamericanas para a condução de programas de saúde, nutrição e saneamento em áreas onde eram instaladas bases militares norte-americanas e em regiões produtoras de matérias-primas estratégicas para a indústria bélica daquele país. O objetivo era desenvolver campanhas de combate a doenças específicas e fornecer assistência médica a soldados e trabalhadores envolvidos nas atividades de extração de borracha e minérios.

Além de angariar o apoio de vários países do continente aos esforços de guerra, a iniciativa estadunidense de cooperação hemisférica tinha outros interesses motivadores, como assegurar a defesa da região diante da ameaça nazista, garantir a segurança dos investimentos norte-americanos e promover as relações interamericanas. Do ponto de vista dos latino-americanos, a oportunidade de contar com o patrocínio e a assistência técnica dos Estados Unidos para a condução de programas sanitários e empreendimentos saneadores não deixava de ser atraente (Quevedo, 2004).

Firmados os acordos, a implementação dos programas se efetivava mediante a criação de um organismo que era conhecido, na maior parte dos países, como Servicio Cooperativo Interamericano de Salud Pública (SCISP) e possuía o caráter de agência internacional, contando com relativa autonomia perante os ministérios e departamentos nacionais de saúde. No Brasil, a instituição oriunda do acordo cooperativo com o Iaia recebeu o nome de Serviço Especial de Saúde Pública (Sesp) e manteve-se em funcionamento de 1942 a 1960, quando a parceria com o organismo estrangeiro expirou e o Sesp foi transformado na Fundação Serviço Especial de Saúde Pública.

É a história do Sesp que André Campos se propõe a contar em Políticas internacionais de saúde na Era Vargas, discutindo a questão sanitária com referência à política interna e ao cenário internacional e preenchendo assim, segundo Nísia Trindade Lima (2002), 'uma lacuna' nos 
estudos sobre as políticas de saúde no período Vargas, dentro de um contexto marcado pela Segunda Guerra Mundial e pelo estreitamento das relações entre Estados Unidos e Brasil. O pioneirismo do estudo de Campos é assinalado ainda por Marcos Cueto em sua apresentação do livro, lembrando que, embora em vários países da América Latina tenham sido estabelecidos serviços de saúde cooperativos nos moldes do Sesp, não havia até o momento uma análise historiográfica detalhada de nenhum deles. Tais referências à obra, aliadas ao primoroso prefácio de Gilberto Hochman, reiteram sua importância para o campo da história social da medicina e saúde pública no Brasil e na América Latina.

Com base em ampla pesquisa arquivística realizada no Brasil e nos Estados Unidos, o autor oferece, na primeira parte do livro, uma reconstituição precisa dos interesses envolvidos na ação cooperativa norte-americana durante a guerra, assim como da estratégia de atuação do Iaia e do papel do governo Vargas na negociação do convênio que deu origem ao Sesp. A segunda parte da obra é dedicada aos programas sanitários lançados pelo Sesp. Somos informados, então, que a agência iniciou suas ações em saúde nas cidades de Belém, Recife e Natal, onde haviam sido instaladas bases militares norte-americanas. A preocupação central era com a malária, doença que ao lado da tuberculose mais vitimava a população local e representava grave ameaça à saúde dos soldados.

O controle da malária também era prioridade da política sanitária conduzida pelo Sesp na região amazônica. Tal política, conhecida como 'Programa da Amazônia', era parte do compromisso estabelecido pelos Acordos de Washington de aumentar a produção de borracha, tendo em vista o abastecimento da indústria bélica norte-americana. As condições sanitárias precárias nas áreas de seringais e a prevalência da malária figuravam entre os principais obstáculos ao incremento da produção de látex e mereceram atenção do Sesp. A estratégia de combate à doença envolveu, em um primeiro momento, a distribuição emergencial de atebrina, intervenções saneadoras no ambiente, a condução de investigações epidemiológicas e estudos entomológicos e, posteriormente, a construção de uma rede de unidades sanitárias ao longo do vale amazônico e o uso do DDT (a partir de 1945).

Os capítulos 4 e 5 versam sobre um episódio polêmico da nossa história, conhecido como a 'batalha da borracha'. Segundo relato de Campos, assim que a campanha da borracha entrou em operação, os funcionários do Iaia no Brasil se deram conta de que, além das ameaças à saúde dos seringueiros, também a escassez de mão-de-obra comprometia a produção de borracha amazônica. Na tentativa de resolver essa questão, os norte-americanos chegaram a cogitar o uso de trabalho indígena nos seringais, consultando para isso o Serviço Nacional de Proteção ao Índio. Finalmente, a alternativa que se mostrou viável foi recorrer aos migrantes, que historicamente já se deslocavam de maneira espontânea para a Amazônia para escapar das secas periódicas que vitimavam alguns estados da região Nordeste.

O Departamento Nacional de Imigração (DNI) passou a organizar o fluxo de famílias de refugiados para a Amazônia e, em outubro de 
1942, representantes do DNI, do Iaia, do Sesp, do governo do estado do Ceará, da Rubber Development Corporation e da Comissão de Controle dos Acordos de Washington lançaram o Programa de Migração do Sesp. Duas novas agências foram criadas com o propósito de intensificar o fornecimento de mão-de-obra para os seringais amazônicos, o Serviço Especial de Mobilização de Trabalhadores para a Amazônia (Semta) e a Superintendência de Abastecimento do Vale Amazônico (Sava), cujas atribuições incluíam o recrutamento de trabalhadores adultos do sexo masculino no Nordeste, seu transporte, encaminhamento e distribuição nas áreas de extração de borracha no Vale Amazônico. O Sesp tinha a incumbência de fornecer assistência médica às famílias migrantes e aos trabalhadores nas estações e alojamentos do DNI e do Semta, e de inspecionar as condições sanitárias desses locais. Cabia ainda aos médicos do Sesp determinar, com base em critérios bastante racistas, se os homens recrutados estavam fisicamente aptos para o trabalho nos seringais.

Certamente o relato da tragédia vivenciada pelos migrantes recrutados para a 'batalha da borracha' é um dos destaques do livro. Nesse ponto, uma narrativa sensível aproxima o leitor da história de homens, mulheres e crianças que, ao participar do programa governamental de transmigração de trabalhadores para os seringais amazônicos, foram submetidos a condições sanitárias degradantes durante a viagem e obrigados a permanecer em locais insalubres, onde muitos contraíram doenças graves e mesmo fatais.

Nos alojamentos do Semta, do DNI e do Sava, por onde os migrantes transitavam, os inspetores do Sesp não raro identificavam uma situação precária, referindo-se a refeições de má qualidade, quantidade insuficiente de alimentos, água imprópria para consumo e falta d'água. Essa situação, aliada às grandes aglomerações que se formavam nesses locais, favorecia a intensa proliferação de doenças. Os migrantes contraíam principalmente infecções respiratórias, doenças entéricas, disenteria, tuberculose, malária e doenças sexualmente transmissíveis. Muitas mortes foram causadas por epidemias de sarampo e febre tifóide que assolaram as estações e os abrigos. No geral, os maiores índices de mortalidade referiam-se às crianças. Alguns relatos são alarmantes:

apenas em abril de 1944 o número de crianças mortas alcançou 35 no alojamento do DNI em Alagadiço, Fortaleza. Neste campo a população atingira a marca de 1.500 pessoas em arriscada situação: a lotação era de 800 . Segundo relatou um médico, vivia-se 'em grande promiscuidade' e em falta de lençóis de flanela e cobertores para crianças. Para completar, houve 'absoluta falta de leite no hospital por 15 dias', e foi impossível alimentar adequadamente as crianças. Os casos de distúrbios digestivos e intoxicação alimentar aguda abundavam, e 'não havia espaço no hospital'. (p.154)

Do mesmo modo que nos abrigos e alojamentos, os migrantes em trânsito estiveram sujeitos a várias situações de risco. Muitas vezes eram transportados expostos às intempéries. Os navios costumavam zarpar superlotados e, neles, a incidência de doenças era alta. Por terra, as viagens eram ainda mais longas e desconfortáveis. No trajeto percorrido de ônibus e caminhão, o comboio que os acompanhavam era for- 
mado somente por guardas sanitários, quase nunca contando com um médico.

Um dos méritos narrativos do autor é o uso apropriado de fontes valiosas, como os relatórios de médicos e sanitaristas do Sesp e as cartas dos próprios 'soldados da borracha' e seus familiares. Entre os relatórios, destacam-se os do médico John Edwards e os do antropólogo Charles Wagley, por ultrapassar o enfoque meramente técnico presente nessa modalidade de documento e oferecer descrições densas, tanto a respeito da grave situação social vivenciada em regiões remotas do sertão nordestino e do vale amazônico, quanto acerca das histórias de vida e experiências dos migrantes recrutados para a 'batalha da borracha'. Wagley foi até mesmo um dos diretores do Programa de Migração e do Programa de Educação Sanitária do Sesp (sobre sua atuação, ver Figueiredo, 2004).

Além do Programa da Amazônia, Políticas internacionais de saúde também avalia o Programa do Rio Doce, lançado pelo Sesp em 1943 como efeito da preocupação com as condições sanitárias nas áreas mineradoras do vale do Rio Doce. Como parte do programa, o Sesp ficou encarregado de sanear o território em torno da estrada de ferro Vitória-Minas, que estava sendo reconstruída para escoar a produção de minério de ferro destinada a suprir a demanda norte-americana pelo produto. $\mathrm{O}$ fornecimento de assistência médica nos acampamentos de trabalhadores e pequenas vilas ao longo da estrada, o controle da malária, os projetos de engenharia sanitária, a formação de visitadoras e enfermeiras, assim como a construção de postos de saúde e hospitais também foram tarefas realizadas pelo Sesp no âmbito do mencionado programa.

Ainda que nos primeiros anos de existência do Sesp suas intervenções sanitárias e políticas de saúde tenham estado fortemente vinculadas aos imperativos de guerra e às expectativas norte-americanas, Campos observa que sempre houve esforços, por parte do governo brasileiro, de aproximar as ações do Sesp do seu projeto nacional. Os Programas da Amazônia e de Migração, por exemplo, não deixaram de servir convenientemente aos propósitos de ocupação do vale, de extensão da autoridade sanitária às regiões mais remotas e de reativação da economia local.

Em outros termos, embora a criação do Sesp tivesse respondido aos problemas imediatos do pós-Segunda Guerra Mundial, devendo a agência, presumivelmente, ter uma existência temporária, Campos argumenta que ela se acomodou tão bem às mudanças na conjuntura internacional e atendeu tão satisfatoriamente às necessidades domésticas em diferentes momentos, que logrou continuar em operação por muito mais tempo do que o inicialmente previsto, ampliando seus objetivos e o escopo de sua ação. Nesse sentido, o autor examina as variáveis externas e internas que permitiram ao convênio sanitário estabelecido entre Brasil e Estados Unidos sobreviver ao desfecho da guerra.

André Campos esclarece que, na década de 1950, novos elementos como a emergência do paradigma do desenvolvimento, o contexto de 'otimismo sanitário' e o impulso à cooperação técnica compuseram um cenário internacional no qual o papel estratégico do Iaia foi reno- 
vado. Com a associação entre saúde e desenvolvimento, os programas sanitários bilaterais patrocinados pelo Iaia na América Latina foram investidos de novos significados e convertidos em experiência modelo para o Ponto IV - a política de assistência ao desenvolvimento do Terceiro Mundo, lançada pelos Estados Unidos durante a Guerra Fria como parte de sua ofensiva anticomunista. Certamente tal configuração internacional criou condições favoráveis à preservação do Sesp, mas a continuidade deste, segundo Campos, dependeu também da resposta que a agência conseguiu dar às exigências impostas pelo governo brasileiro, cuja estratégia buscava articular cada vez mais intervenções sanitárias a uma política de promoção de desenvolvimento e integração nacional.

Os capítulos finais abordam o período de consolidação e expansão das atividades do Sesp, quando a agência passou a estabelecer convênios com governos estaduais e municípios, investir em novas áreas como a engenharia sanitária e ampliar a preocupação com qualificação de pessoal, além de desenvolver programas de educação sanitária e dar continuidade à política de implantação de redes de unidades de saúde através do Brasil. Enfim, o autor examina um conjunto de intervenções que atestam o papel proeminente desempenhado pelo Sesp no processo de institucionalização das políticas públicas de saúde no país.

Em resumo, Campos analisa a história da instituição discutindo sua atuação no âmbito da saúde em relação tanto às expectativas internacionais quanto às diretrizes nacionais. Filia-se a uma linha de pesquisa que reconhece, nas instituições internacionais, arenas de poder cujos enunciados não se impõem simplesmente nos países onde atuam, mas também deixam espaço para processos de disputa, conflito, negociação e acomodação. Sob tal premissa, o autor ressalta que a existência, no Brasil, de um Estado que expandia sua presença no território, bem como a presença de uma tradição sanitária nacional e uma experiência administrativa local na área de saúde foram determinantes para a orientação das ações do Sesp. Desse modo, Campos adverte que, na avaliação do papel desempenhado pelo Sesp, deve-se não somente considerar as condições externas que dizem respeito aos interesses do governo norte-americano, aos esforços de guerra e à assistência internacional para o desenvolvimento, mas também - algo imprescindível - atentar para o cenário interno marcado pelo projeto de construção nacional (nation building), pela política de fortalecimento da autoridade estatal e de promoção do desenvolvimento econômico durante a era Vargas:

a continuidade do Sesp significou, para a agência, incorporar-se aos planos regionais de desenvolvimento do Estado brasileiro, implementados, principalmente, em regiões mais carentes do país, especialmente o Nordeste e a Amazônia, na década de 1950. Ao provir de infra-estrutura sanitária básica aquelas regiões, o Sesp prosseguia sendo um instrumento de expansão da autoridade pública no país. (p.274-275)

Em outras palavras, o autor refuta a tese de que o Sesp seria um mero instrumento do imperialismo ianque no Brasil - uma acusação 
dirigida à instituição ao longo de sua trajetória. Em nenhum momento, segundo ele, o fato de o Sesp ser uma agência bilateral o impediu de entrar em sintonia com a agenda de saúde forjada pelo governo brasileiro. Pelo contrário, o organismo acabou dando continuidade ao processo de interiorização dos serviços de saúde no país. A estratégia do Sesp, defende Campos, foi valer-se da influência e dos recursos norteamericanos para articular um modelo de administração sanitária e de saúde pública que, a despeito de não ter se mantido imune a críticas, tornou-se uma referência para o país.

Em Políticas internacionais na era Vargas, André Campos executa com maestria a tarefa de analisar a história de uma instituição importante, envolta em muita controvérsia e pouco estudada. Além de dar conta de todas as facetas do Sesp e de associar um trabalho historiográfico irretocável a uma linha argumentativa crítica, o livro tem ainda o diferencial de revelar ao leitor a dimensão humana e trágica da história da saúde pública e das políticas sanitárias no país.

\section{REFERÊNCIAS BIBLIOGRÁFICAS}

Figueiredo, Regina

É.D. de

Lima, Nísia Trindade 2002

Quevedo, Emílio et al. 2004
Cuidando da saúde do vizinho: as atividades de antropólogos norte-americanos no Brasil. Dissertação (Mestrado) - Universidade de Campinas, Campinas.

O Brasil e a Organização Pan-Americana da Saúde: uma história em três dimensões. In: Finkelman, Jacobo (Org.). Caminhos da saúde pública no Brasil. Rio de Janeiro: Ed. Fiocruz. p.24-116.

Café y gusanos, mosquitos y petróleo: el transito desde la higiene hacia la medicina tropical y la salud pública en Colombia, 1873-1953. Bogotá: Instituto de Salud Publica e Centro de Historia de la Medicina/ Universidad Nacional de Colômbia. 